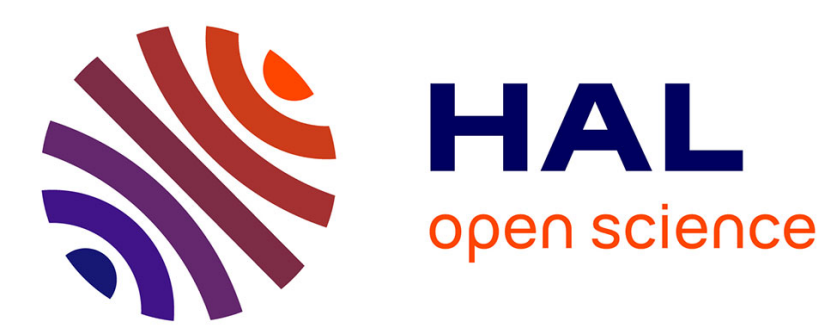

\title{
Controlled electrochemical gas bubble release from electrodes entirely and partially covered with hydrophobic materials
}

Charles Brussieux, Philippe Viers, Herve Roustan, Mohammed Rakib

\section{To cite this version:}

Charles Brussieux, Philippe Viers, Herve Roustan, Mohammed Rakib. Controlled electrochemical gas bubble release from electrodes entirely and partially covered with hydrophobic materials. Electrochimica Acta, 2011, 56 (20), pp.7194-7201. 10.1016/j.electacta.2011.04.104 . hal-00642540

\author{
HAL Id: hal-00642540 \\ https://hal.science/hal-00642540
}

Submitted on 18 Nov 2011

HAL is a multi-disciplinary open access archive for the deposit and dissemination of scientific research documents, whether they are published or not. The documents may come from teaching and research institutions in France or abroad, or from public or private research centers.
L'archive ouverte pluridisciplinaire HAL, est destinée au dépôt et à la diffusion de documents scientifiques de niveau recherche, publiés ou non, émanant des établissements d'enseignement et de recherche français ou étrangers, des laboratoires publics ou privés. 


\title{
Controlled electrochemical gas bubble release from electrodes entirely and
} partially covered with hydrophobic materials

\author{
Brussieux $\mathrm{C}^{\mathrm{x}}$., Viers Ph. ${ }^{\mathrm{x}}$, Roustan $\mathrm{H}^{+}{ }^{+}$,Rakib M. ${ }^{* x}$ \\ ${ }^{x}$ Ecole Centrale Paris, Laboratoire de Génie des Procédés et Matériaux \\ Grande Voie des Vignes, 92295 Châtenay-Malabry Cedex \\ ${ }^{+}$Rio-Tinto Alcan Aluval-EMRA \\ 725 rue Aristide Berges BP 7-38341 Voreppe Cedex
}

\section{Abstract}

This paper deals with an experimental study on millimetre-size electrochemically evolved hydrogen bubbles. A method to generate gas bubbles controlled in number, size at detachment and place on a flat electrode is reported. Partially wetted composite islands are implemented on a polished metal substrate. As long as the island size is lower than a limit depending on its wettability, only one bubble spreads on the island and its size at detachment is controlled by the island perimeter. The composite, a metal-polytetrafluoroethylene (Ni-PTFE), is obtained by an electrochemical co-deposition process. On the contrary to predictions of available models for co-deposition, at current densities beyond $\mathrm{Ni}^{2+}$ limiting current density, the mass ratio of PTFE in the deposit strongly increases. A mechanism is proposed to describe co-deposition when hydrogen bubbles are co-evolved. The observation of gas evolution on fully hydrophobic electrodes highlights the fact that bubbles growth rate on such electrodes differs from growth rates when bubble growth is controlled by mass transport of dissolved gas. The more a bubble grows by coalescence the more its foot expands on the electrode the bigger its size at detachment. This triple line creeping mechanism explains why, when attached bubbles coalesce many times before detaching, their size at detachment increases with current density.

\footnotetext{
* Corresponding author, Tel +33 1411315 56; e-mail: mohammed.rakib@ecp.fr
} 
Keywords: gas evolving electrode, Ni PTFE, controlled bubbles, wettability, hydrophobic electrode

\section{Introduction}

Electrochemical gas evolution was studied thoroughly in aqueous solutions for its applicability in numerous industrial processes [1-4]. This study was undertaken with the aim to gain new insights on four persistent problems in the description of gas evolving electrolysis, namely:

- Most of the available data and models refer to hydrogen, oxygen and chlorine evolving in the form of small bubbles on well wetted electrode materials. These descriptions are irrelevant to characterize bubbles observed during electrolysis in molten salts. To illustrate this point, fluorine bubbles obtained in KF2HF melts are described in [5].

- Despite recent developments [6-9] enabling a precise mathematical description of attached bubbles and drops by overcoming the boundary condition problem in fluid mechanics equations brought by the infinite viscous diffusion at the triple line [10], modelling the bubbles size at detachment remains an open question [11]. In aqueous electrolytes with well wetted electrode materials the anchoring area of electrochemically evolved bubbles is difficult to observe and consequently was rarely studied.

- Models of gas evolving electrolysers are becoming more and more reliable thanks to the use of Eulerian or Lagrangian descriptions of the disperse phase flow. See [12-13] for recent examples. However, the amplitude of the forces responsible for the variations of the width of the bubble plume is still a subject of discussion [14]. As a consequence, the lift force and turbulent dispersion forces are used to tune models implying that experimental checks are required. 
- To the best of our knowledge, a simple way to obtain gas bubbles which are controlled in number, size at detachment and place on a flat electrode during water electrolysis was never reported. Repeatable bubbles were obtained by water electrolysis on a small electrode when only one bubble settles on the electrode; this has been illustrated in various aspects [15-18]. On flat electrodes, artificial cavities or the border of the electrode can be used to obtain repeatable bubbles [19-20] in small number and with small size at detachment. Electrodes on which the average bubble size at detachment is controlled have been reported [21-23] but the exact number of bubbles and the size of each bubble were not known.

This study is focused on a way to obtain a highly hydrophobic electrode material to examine the gas release on electrodes with a high gas coverage on which the bubble anchoring area are viewable and the detached populations shifted to higher size. The gas release was examined on two kinds of electrodes, electrodes fully covered with a hydrophobic material and electrodes partially covered with hydrophobic material. On the second kind of electrodes, bubbles from the hydrophobic material are controlled in number and size at detachment.

\section{Experimental details}

\subsection{Hydrophobic electrode preparation and testing}

Square $2.25 \mathrm{~cm}^{2}$ copper electrodes bordered with epoxy resin were covered with a cathodic deposit of Ni-PTFE composite. The cell was cubic and contained 0.75 $\mathrm{L}$ of the bath proposed by Bouazaze et al. [23]. The bath is composed of a PTFE suspension supplied by Aldrich (60\% mass) and of a solution of $\mathrm{NiSO}_{4} 0.26 \mathrm{~mol} \mathrm{~L}^{-1}$, $\mathrm{H}_{3} \mathrm{BO}_{3} 0.11 \mathrm{~mol} \mathrm{~L}^{-1}, \mathrm{NH}_{4} \mathrm{Cl} 0.11 \mathrm{~mol} \mathrm{~L}^{-1}$, Triton X100 $0.01 \mathrm{~mol} \mathrm{~L}^{-1}$ in water at $\mathrm{pH} 6$. Thirty electrodes were prepared varying the PTFE suspension mass ratio from 0 to 
$40 \%$ and the average deposition current density between 25 and $600 \mathrm{~A} \mathrm{~m}^{-2}$. Each deposition was carried out under galvanostatic control with an Autolab PGSTAT30 potentiostat/galvanostat for 30 minutes. The anode was a flat $8 \mathrm{~cm}^{2}$ nickel electrode. The anode and the cathode were parallel with a $1 \mathrm{~cm}$ gap. The bath was stirred.

After the deposition process the electrodes were cleaned in an ultrasonic bath containing ethanol $95 \%$. A white lightly-green crust which can form at cathodic current densities beyond $150 \mathrm{~A} \mathrm{~m}^{-2}$ was then scraped to reveal a shiny black deposit.

In order to characterize these deposits, three types of measurements were performed.

- The wettability of the deposits was measured with a TECLIS tensiometer using a dynamic sessile distilled water drop contact angle measurement. The sessile drop volume was initially $5 \mu \mathrm{L}$ and then successively filled and drained at $0.1 \mu \mathrm{L} \mathrm{s} \mathrm{s}^{-1}$ between the advancing and receding contact angle.

- The deposits surface was observed using a scanning electron microscope with a field emission gun (SEM-FEG).

- The $\mathrm{H}_{2}$ gas release during water electrolysis was observed on the deposits with a technique described in $\$ 2.3$.

\subsection{Design of an electrode partially covered with hydrophobic islets using photolithography and electrochemical co-deposition}

A hydrophobic material was deposited on disc shaped islands with a photolithographic method on flat copper electrodes. The electrodes were the face of a $28 \mathrm{~mm}$ diameter polished copper disc. The borders of the disc were embedded with an insulating resin which wets metal well. A photoresist was sprayed on the electrode. After a drying time the electrode was exposed to UV light under a negative transfer paper mask and then revealed. Different mask layouts have been tested. 
Mask layout examples are shown in figure 1. On figure 1-(A), rows of pairs of anchoring sites were placed with an increasing gap, this layout was used to observe the impact of coalescence on bubble size at detachment. The layout on figure 1-(B) was used to observe the impact of the hydrophobic islet size on bubble size at detachment.

Although the deposition technique used is slightly different than previously (§2.1), the cell, bath composition and stirring were unchanged. A disc electrode was horizontal facing upwards at $3 \mathrm{~cm}$ from the anode. A L-shaped saturated calomel reference electrode was used to control the deposition potentiostatically. Hereafter the potentials are expressed after ohmic drop correction. The deposits on the unmasked part of the electrode were realised with 100 cycles of $30 \mathrm{~s}$ at $E_{\text {dep }}=-1.25$ $\mathrm{V} / \mathrm{SCE}$ followed by $30 \mathrm{~s}$ at $-0.6 \mathrm{~V} / \mathrm{SCE}$ with a potentiostat. Experimentally, at -1.25 V / SCE the average deposition current density on the unmasked surface is between 300 and $600 \mathrm{~A} \mathrm{~m}^{-2}$ whatever the mask layout and the deposition conditions. After deposition the photoresist was cleaned. The electrode was rinsed with $95 \%$ ethanol and dried.

\subsection{Gas release observation and bubble size measurement}

A cubic transparent polycarbonate $10 \mathrm{~cm}$ large cell was filled with $0.85 \mathrm{~L}$ of 0.5 $\mathrm{mol} \mathrm{L}^{-1} \mathrm{NaOH}$. The electrodes were conditioned for $500 \mathrm{~s}$ at $500 \mathrm{~A} \mathrm{~m}^{-2}$. Electrolysis was realised under galvanostatic control. Hydrogen was evolved at the cathode and oxygen at the anode. The modified electrode was mounted as a cathode. The anode was a $3 \mathrm{~cm}$ diameter graphite disc parallel to the cathode at a distance of $6 \mathrm{~cm}$. The cell was splitted into two compartments with a Z-shaped filter paper. The cell could rotate at $180^{\circ}$ around the observation axis, tangential to the cathode. When not specified, the results have been obtained with a horizontal electrode facing upwards. 
Any bubbles present in the cell were removed prior to experiment. The observations were done with a high speed camera (PCO 1200hs) mounted on a microscope (Zeiss STEMI SV-11) placed on a horizontal rack. A mirror may be placed between the electrodes for direct periscope observations of the gas release. The electrodes were illuminated with a fiber optic cold light source.

Lengths were measured directly on the image after a calibration. An image processing software was used (ImageJ). If the bubble surface was well defined in the picture and when the measured bubble presented a symmetry axis in the picture plane, the bubble equivalent radius was estimated from its shape on the picture. When bubbles did not present a symmetry axis in the picture, the following procedure was used to estimate their size.

1- Measurement of the two axes lengths of the smallest circumscribed ellipse to the bubble (a1; a2)

2- Measurement of the two axes lengths of the biggest inscribed ellipse in the bubble (a3; a4)

3- The volume of the bubble was approximated with relation 1 :

$$
V_{\text {beq }} \approx \frac{1}{2}\left[\frac{4 \pi}{3} \min (a 1 ; a 2)^{2} \max (a 1 ; a 2)+\frac{4 \pi}{3} \min (a 3 ; a 4)^{2} \max (a 3 ; a 4)\right] \text { (1) }
$$

and the equivalent radius $r_{\text {eq }}$ obtained with relation 2 :

$$
r_{e q}=\sqrt[3]{\frac{3}{4 \pi} V_{b e q}}
$$




\section{Results and discussion}

\subsection{Hydrophobic deposits, impact of the current density during deposition on PTFE mass ratio and wettability}

The PTFE distribution on the deposits surface was observed with SEM-FEG. In the pictures presented hereafter in figures 2, 3 and 4 the PTFE appears in the form of blurred rounded patterns. We define the current density during deposition $j_{\text {dep }}$ as the ratio of the cell current to the initial geometrical electrode surface.

-The deposits prepared with current density $j_{\text {dep }}<100 \mathrm{~A} \mathrm{~m}^{-2}$ are very porous with pores similar to those obtained using similar deposition bath without PTFE [24]. Those deposits have a metallic grey visual aspect and PTFE is present on dispersed micrometric clusters and in the pores. An example of SEM-FEG pictures of such a deposit is given in figure 2 .

- Near $\mathrm{j}_{\mathrm{dep}}=100 \mathrm{~A} \mathrm{~m}^{-2}$ the deposits are columnar. The Ni columns width decrease but their heights increase with increasing current densities and PTFE clusters are present at the columns base. Those deposits have a grey-dark or a grey marbled visual aspect. Examples are given in figure 3. In this figure the columns size and PTFE clusters at the columns base appear clearly.

- For $j_{\text {dep }}>150 \mathrm{~A} \mathrm{~m}^{-2}$ the deposits are covered with a white, light green and not adhesive crust composed mostly of PTFE. Once the crust removed, a shiny black deposit appears. This deposit is composed with a dense thin nickel dendrites network with PTFE filling the inter dendrites spaces. Pictures of a shiny black deposit are given in figure 4.

Figure 5 shows the measured advancing and receding contact angles of a deionised water droplet on the deposits versus the average current density during the co-deposition process for the whole experimental range of PTFE suspension mass- 
ratio in the deposition bath. Until $j_{\text {dep }}=100 \mathrm{~A} \mathrm{~m}^{-2}$, the deposit wettability increases with an increasing deposition current density. This increase in wettability denotes a decrease in the PTFE mass-ratio in the deposit in agreement with an existing model [25] assuming a mechanism of adsorbed particles entrapment for Ni-PTFE electrochemical deposition or with a sedimentation co-deposition mechanism [23]. At current densities higher than $100 \mathrm{~A} \mathrm{~m}^{-2}$ the electrode material wettability decreases again and is very small when the deposition current density is higher than approximately $300 \mathrm{~A} \mathrm{~m}^{-2}$.

To explain the increase in PTFE ratio in the deposits beyond $100 \mathrm{~A} \mathrm{~m}^{-2}$, we propose the following mechanism consisting of the combined intervention of three phenomena. The first process of the mechanism is the destabilisation of the PTFE suspension in the bath by growing $\mathrm{H}_{2}$ bubbles. During this step the surfactants stabilizing the PTFE suspension are captured at the bubbles/electrolyte interfaces letting the PTFE particle free to aggregate. The second process is the aggregation of free PTFE particles with clusters of PTFE particles on the electrode surface. The last phenomenon is the electrochemical growth of the Ni deposit trapping the clusters at the surface. Such a mechanism would lead to a PTFE content related to the surface of $\mathrm{H}_{2}$ bubbles evolved. A complementary experiment proved that metal deposition is not necessary for the formation of PTFE clusters on a metal cathode. During this experiment the formation of pure PTFE clusters on a pure Ni cathode was observed after water electrolysis in a bath composed of PTFE suspension and $\mathrm{NaOH}$.

\subsection{Gas release from an electrode fully covered with a hydrophobic deposit}

An electrode prepared as described in $\$ 2.1$ will be called a hydrophobic electrode. The current density during water electrolysis $j_{w e l}$ is the ratio of the cell current during water electrolysis to the geometrical electrode surface taking into 
account the surface covered with Ni-PTFE and the uncovered surface when this last one exists. The size distribution of the $\mathrm{H}_{2}$ bubbles population during water electrolysis on these electrodes was measured. A Ni-PTFE electrode prepared at high deposition current density evolved large size $\mathrm{H}_{2}$ bubbles, their diameter can attain one centimeter. Figure 6 presents pictures of a $5.5 \mathrm{~mm}$ equivalent diameter $\mathrm{H}_{2}$ bubble before and after detachment from a shiny black Ni-PTFE electrode material.

A striking aspect of the gas release from highly hydrophobic electrodes is the high gas coverage and the very important link between bubble size at detachment and current density. The high gas coverage implies that bubbles grow more due to coalescence rather than from mass transport with dissolved gas. The coalescence of two bubbles produces a third bubble. Considering that the biggest of the two initial bubbles is the third bubble, the volume of this locally biggest bubble increases linearly with time. Between important size fluctuations, the mature bubbles equivalent radius is proportional to the cube root of residence time and the growth rate is a function of average current density $j_{\text {wel }}$ and anchoring area circumference. This aspect of gas release at hydrophobic electrodes is in contrast to the common aqueous gas evolving electrolysis case where the growth is due to dissolved gas mass transfer from the electrode to the bubble surface. In this common case the bubble radius is proportional to the square root of residence time and the growth rate is a function of gas supersaturation in the bubble vicinity [26-28].

Since on highly hydrophobic electrodes, the triple line is observable without experimental effort it was possible to notice that besides the fact that bubble size at detachment is a function of the electrode material wettability, the bubble size at detachment turns out to be highly dependent on the growth dynamics of its triple line. The outcome of coalescence is generally an increase in triple line length or the 
bubble detachment. When coalescence does not lead to a detachment, the smaller the detaching/attaching force ratio, the higher the ratio between the two triple lines length before coalescence and the triple line length after coalescence. An impacting parameter is the volume ratio between the two bubbles. When both volumes are similar, the triple lines position changes more than when the two coalescing bubbles volumes are very different. This phenomenon is schematically depicted in figure 7 but would deserve a mathematical description. As long as the detachment forces tend to increase with bubble volume, most increase in triple lines lengths occurs in the early moments after nucleation. Mature bubbles approaching their size at detachment only see their triple line modified if coalescence occurs with a similar size bubble.

The coalescence frequency between attached bubbles is related to the rate of gas evolution, thus bubble triple line length growth rate increases with increasing current density. As long as the bubble size at detachment is increasing with increasing triple line length, the bubble size at detachment is increasing with increasing current density. This effect is especially pronounced on hydrophobic electrodes as shown in figure 8.

\subsection{Gas release observations from a partially covered electrode}

The copper electrode partially covered with Ni-PTFE islets produce small $\mathrm{H}_{2}$ bubbles from the uncovered surface and bigger $\mathrm{H}_{2}$ bubbles from the composite islets. As long as the hydrophobic islands are sufficiently small, only one large bubble settles on each hydrophobic islands of the electrode. The biggest covered islands depend on the detaching/anchoring forces ratio; the detaching forces are buoyancy and hydrodynamic forces. In stagnant $\mathrm{NaOH}$, the largest hydrophobic islets covered with only one bubble on a flat electrode facing upwards were $2 \mathrm{~mm}$ in diameter. Bubbles covering a hydrophobic disc are formed by the coalescence of micrometre 
dimension bubbles which have nucleated on the entire hydrophobic site surface. This site-covering step is very short in duration compared to the residence time of the formed bubble. As a consequence there is no waiting time between a detachment and the following nucleation for the bubbles attached at the Ni-PTFE discs. At this point, the bubbles attached on the Ni-PTFE islets differ from the common nucleation behaviour on a nucleation site for which a waiting time can be observed between a detachment and the successive nucleation [28]. Therefore strictly speaking the term "waiting time" is not appropriate since there is not only one nucleation site on the hydrophobic islet. In stagnant electrolyte at current densities lower than $j_{\text {wel }} \approx 50 \mathrm{~A} \mathrm{~m}^{-}$ ${ }^{2}$ nucleation only occurs on those hydrophobic islands. Beyond $\mathrm{j}_{\mathrm{wel}} \approx 50 \mathrm{~A} \mathrm{~m}^{-2} \mathrm{H}_{2}$ is evolved on the entire electrode but the $\mathrm{H}_{2}$ bubbles from the copper part of the electrode are of about $20-100 \mu \mathrm{m}$ in diameter and do not modify the behaviour of bubbles settling on hydrophobic islands below $\mathrm{j}_{\text {wel }}=20 \mathrm{kA} \mathrm{m}^{-2}$. Figure 9 presents the measured bubble equivalent radius for eleven consecutives bubbles from the same anchoring site versus time compared to an optimised $r_{e q}=K \sqrt{t_{r, e l}}$ law. For this measurement the sampling frequency was not sufficient to observe the radius at the very first moments of the bubble life but the absence of a noticeable "waiting time" is observed.

The detachment size and contact angle before detachment were controlled by the perimeter of the bubble triple line length. If a bubble fully covers a hydrophobic disc its size at detachment is controlled by the islet perimeter. Figure10-(A) presents a plot of bubbles' volume at detachment versus the anchoring site perimeter on electrodes covered with hydrophobic islets varying in size. The data are compared with a fitted linear and a fitted $3 / 2$ power law. The contact angle varies all along the bubble life. Figure 10-(B) is the plot of measured radius at detachment versus contact 
angle just before detachment and compares the results with the well known correlation 3 [29]. It confirms that the contact angle at detachment of an axisymmetric bubble is an indirect measure of the bubble anchoring zone.

$$
r_{d}=0.0104 \theta_{d} \sqrt{\sigma /(g \Delta \rho)}
$$

The observation of bubbles coalescing from their equatorial diameter as shown in Figure 11-(A) lead to the conclusion that two neighbouring bubbles behave in different ways depending on the distance between their anchoring line and their site size. These observation are summarized by figure 11-(B) which presents results obtained with $r_{s}=150 \mu \mathrm{m}$ at $j_{\text {wel }}=10 \mathrm{~A} \mathrm{~m}^{-2} \cdot r_{\mathrm{di}}$ is the radius at detachment from a single site producing a single bubble not subjected to coalescence, $L$ is the smallest distance between sites centre. The following details are observed:

- $\mathrm{L} / 2<0.2 \mathrm{r}_{\mathrm{di}}$ the newly formed bubble remains attached on the two sites and then will detach at a radius greater than $r_{d i}\left(r_{s}=150 \mu \mathrm{m}\right)$.

- $0.2 r_{\mathrm{di}}<\mathrm{L} / 2<0.4 \mathrm{r}_{\mathrm{di}}$ the newly formed bubble can remain on the two sites or can remain on one site or can detach.

- $0.4 r_{\mathrm{di}}<\mathrm{L} / 2<0.6 \mathrm{r}_{\mathrm{di}}$ the newly formed bubble can only remain on one site or detach. When the bubble remains on only one hydrophobic islet its size at detachment tends to be lower than $r_{d i}$ because of further coalescence with other bubbles forming at the second islet.

- $0.6 r_{\mathrm{di}}<\mathrm{L} / 2<\mathrm{r}_{\mathrm{di}}$ the newly formed bubble always detach. This aspect is interesting because it highlights the importance of dynamic effects on the outcome of coalescence. When coalescence occurs between two bubbles whose radii are $r \geq 2^{-1 / 3} r_{\mathrm{di}}$, the sum of their volume is higher or equal than $\mathrm{Vbi}$ and the occurrence of detachment is understandable. The fact that bubbles can detach at coalescence with radii below $2^{-1 / 3} r_{d i}$ is thus proof of the impact 
of dynamic effects. Such experiments are a way to quantify the impact of dynamic effects on triple lines behaviour and are of interest to benchmark models which are still to be developed.

- $L / 2>r_{d i}$ no coalescence occurs and $r_{d}=r_{d i}$

Such a finding is not providing a deep insights in the bubble size at detachment problem but could be useful to benchmark future mathematical tools inspired from [69] which are required to solve the problem of bubble size at detachment. This problem must be solved to allow the simulation of processes at gas evolving electrodes.

\section{Conclusion}

A new method to produce repeatable bubbles growing from supersaturation was assessed. The method consists of the creation of anchoring sites where wettability is subjected to significant microscopic variations on a well wetted material. The anchoring properties of the material are related to the biggest area covered by a bubble or the biggest bubbles at detachment or to the maximum bubble contact angle observed before detachment. We have observed that coalescence can lower drastically bubble size at detachment. Depending on the anchoring properties of the material and distance between bubbles, coalescing bubbles can remain attached and cover a bigger electrode area or detach within a period of the gravito-capillary oscillations of the newly formed bubble. Such controlled bubbles are of interest for the study of gas evolving electrodes, and particularly, the study of electrode screening, ohmic drop and mass transfer processes. A controlled population of attached bubbles allow to envisage the development of experimental checks for bubble induced mass transfer models [1,2], supersaturation lowering effect of 
attached bubbles [30] and gas evolution efficiency models [31-32]. Such bubbles also facilitate surface tension measurements by the pendant bubble method.

The study of gas release during water electrolysis from a hydrophobic electrode is of interest because of its similarity with gas release in some molten salt electrolysis. The study highlights the fact that bubble dynamics on partially wetted electrode is very different to bubble dynamics from well wetted electrodes. On hydrophobic electrodes the bubble size at detachment increase with increasing current density because of a relation between bubble anchoring zone and nucleation frequency. Between large size changes due to coalescence with same size bubbles, bubbles volume increase linearly with time proportionally to bubble circumference and to gas evolution rate.

The Ni-PTFE electrochemical deposition was studied to obtain a hydrophobic charge-conducting surface. It was shown that at very high current density large PTFE clusters are formed. It was suggested that this phenomenon results from the destabilisation of PTFE suspension by the co-evolved gas.

\section{List of symbols}

\section{Dimensional quantities:}

d Diameter

(m)

E Electrode polarisation

( $V$ vs. reference)

g Earth gravitational acceleration $\sim 9.81$

$\left(\mathrm{m} \mathrm{s}^{-2}\right)$

j $\quad$ Current density

$\left(\mathrm{A} \mathrm{m}^{-2}\right)$

$K$

Bubble growth rate coefficient

$\left(\mathrm{m} \mathrm{s}^{-1 / 2}\right)$

$L$

Distance between two nearest Ni-PTFE islets' centre

\section{$r$}

Radius

$t$

Time 


$\begin{array}{lll}V & \text { Volume } & \left(\mathrm{m}^{3}\right) \\ \theta & \text { Contact angle } & \left({ }^{\circ}\right) \\ \sigma & \text { Surface tension liquid-gas interface here } \sim 7.510^{-2}\left(20^{\circ} \mathrm{C}\right) & \left(\mathrm{N} \mathrm{m}^{-1}\right) \\ \Delta \rho & \text { Density difference between electrolyte and gas } \sim 10^{3} & \left(\mathrm{~kg} \mathrm{~m}^{-3}\right)\end{array}$

\section{Subscripts:}

$\begin{array}{ll}\text { c } & \text { At coalescence } \\ \text { d } & \text { At detachment } \\ \text { dep } & \text { Deposition } \\ \text { el } & \text { Electrode } \\ \text { eq } & \text { Equivalent } \\ \text { i } & \text { Isolated - not coalescing } \\ \text { r } & \text { Residence } \\ \text { s } & \text { Ni-PTFE disc shaped island } \\ \text { wel } & \text { Water electrolysis }\end{array}$

Other:

max, min Maximum and minimum functions

\section{Bibliography}

[1] H. Vogt, in: E. Yeager (Ed.) , J. O. M. Bockris (Ed.) , B. E. Conway (Ed.) Comprehensive treatise of electrochemistry, Vol. 6, Plenum Press, New York, 1983.

[2] P. J. Sides, in B. E. Conway (Ed.), J. O. M. Bockris (Ed.) and R. E. White (Ed.) Modern aspects of electrochemistry, Vol.18, Springer, Berlin, 1987.

[3] H. Wendt, G. Kreysa, in Electrochemical Engineering, Springer, Berlin, 1999

[4] H. Vogt, G. Kreysa, Electrochemical reactors, in: Ullmann's Encylopedia of Industrial Chemistry, Wiley, Weinheim, 2008. 
[5] H. Groult, J. Fluorine Chem. 119 (2003) 173.

[6] E. B. Dussan, R. T. P. Chow, J. Fluid Mech. 137 (1983) 1.

[7] E. B. Dussan, J. Fluid Mech. 151 (1985) 1.

[8] P. D. M. Spelt, J. Comput. Phys. 207 (2005) 389.

[9] J. B. Dupont, D. Legendre, J. Comput. Phys. 229 (2010) 2453.

[10] C. Huh, L. E. Scriven, J. Colloid Interface Sci. 35 (1971) 85.

[11] H. Vogt, Electrochim. Acta 34 (1989) 1429.

[12] F. Jomard, J. P. Feraud, J. Morandini, Y. D. T. Couvat, J. P. Caire, J. Appl. Electrochem. 38 (2008) 297.

[13] T. Nierhaus, H. Van Parys, S. Dehaeck, J. Van Beeck, H. Deconinck, J.

Deconinck, A. Hubin, J. Electrochem. Soc. 156 (2009) 139.

[14] T. Hibiki, M. Ishii, Chem. Eng. Sci. 62 (2007) 6457.

[15] H. F. A. Verhaart, R. M. Dejonge, S. J. D. Vanstralen, Int. J. Heat Mass Transfer 23 (1980) 293.

[16] C. W. M. P. Sillen, Thesis, Eindhoven Technical University, Eindhoven, 1983.

[17] N. P. Brandon, G. H. Kelsall, J. Appl. Electrochem. 15 (1985) 475.

[18] R. L. Stover, Thesis, Ernest Orlando Lawrence Berkley National Laboratory, Berkley, 1996.

[19] A. Volanschi, W. Olthuis, P. Bergveld, Sens. Actuators, A 52 (1996) 18.

[20] C. Gabrielli, F. Huet, R. P. Nogueira, Electrochim. Acta 50 (2005) 3726.

[21] O. Teschke, F. Galembeck, J. Electrochem. Soc. 131 (1984) 1095.

[22] M. U. Kleinke, M. A. B. de Moraes, O. Teschke, J. Electrochem. Soc. 133 (1986) 1815. 
[23] H. Bouazaze, S. Cattarin, F. Huet, M. Musiani, R. P. Nogueira, J. Electroanal.

Chem. 597 (2006) 60.

[24] F. Huet, M. Musiani, R. P. Nogueira, J. Solid State Electrochem. 8 (2004) 786.

[25] P. Bercot, E. Pena-Munoz, J. Pagetti, Surf. Coat. Technol. 157 (2002) 282.

[26] L. E. Scriven, Chem. Eng. Sci. 10 (1959) 1.

[27] J. P. Glas, J. W. Westwater, Int. J. Heat Mass Transfer 7 (1964) 1427.

[28] W. M. Buehl, J. W. Westwater, AIChE J. 12 (1966) 571.

[29] W. Fritz, Phys. Z. 36 (1935) 379.

[30] Dukovic J., Tobias C. W., J. Electrochem. Soc. 134, (1987) 331

[31] Vogt H., Electrochim. Acta, 56 (2011) 1409

[32] Vogt H., Electrochim. Acta, 56 (2011) 2404

\section{Acknowledgments}

This work was done within the framework of the project MAPR-0022 AMELHYFLAM.

The authors want to acknowledge the ANR (Agence Nationale pour la Recherche) for its financial support and to thank all the partners involved in the project. 
Figures captions

Figure 1: Scheme of positive masks used for insulation

Figure 2: SEM-FEG picture of a deposit surface prepared with à $40 \%$ mass PTFE suspension bath with a current density lower than $100 \mathrm{~A} \mathrm{~m}^{-2}$ showing the porosity of those deposits

Figure 3: SEM-FEG picture of deposits surface prepared with à $40 \%$ mass PTFE suspension bath with a current density between $100 \mathrm{~A} \mathrm{~m}^{-2}$ and about $300 \mathrm{~A} \mathrm{~m}^{-2}$. Black arrows are pointing at PTFE particles

Figure 4: SEM-FEG picture of deposits surface prepared with à $40 \%$ mass PTFE suspension bath with a current density beyond $300 \mathrm{~A} \mathrm{~m}^{-2}$. Most hydrophobic deposit produced

Figure 5: Impact of average current density during the Ni-PTFE co-deposition on measured advancing and receding contact angles

Figure 6: Consecutive pictures of a $5.5 \mathrm{~mm}$ diameter bubble detaching from a $\mathrm{Ni}-$ PTFE cathode at $j_{\text {wel }}=7 \mathrm{kA} \mathrm{m}^{-2}$ prepared at $\mathrm{j}_{\text {dep }}=300 \mathrm{~A} \mathrm{~m}^{-2}-$ Small $\mathrm{H}_{2}$ bubbles are evolved from the border line of the electrode and big bubbles from the electrode center

Figure 7: Schematic description of the outcome of coalescence between attached bubbles

Figure 8: Plot of the average detached bubble equivalent radius (continuous line) and extremal detached radius (dashed line) from a Ni-PTFE prepared at $\mathrm{j}_{\mathrm{dep}}=300 \mathrm{~A} \mathrm{~m}^{-2}$ versus average current density during water electrolysis - Bubbles from the electrode border not taken into account 
Figure 9: Equivalent radius of a bubble growing from a site versus time at $200 \mathrm{~A} \mathrm{~m}^{-2}$, comparison with a $r=\mathrm{K} \mathrm{t}_{\mathrm{r}}^{0.5}$ optimised model

Figure $10(\mathrm{~A})$ : Bubble volume at detachment versus hydrophobic islet perimeter from three different electrodes $(\odot, \bullet, \times)$ at $j_{\text {wel }}=10 \mathrm{~A} \mathrm{~m}^{-2}$

(B): Bubble radius at detachment versus contact angle before detachment at $\mathrm{j}_{\mathrm{wel}}=10$ A $\mathrm{m}^{-2}$ from three different electrodes $(\odot, \bullet, \times)$ compared to the Fritz correlation [29] (dashed line)

Figure $11(\mathrm{~A})$ : A sequence of photos of the same electrode on which bubbles in rows are coalescing from their equator with an increasing distance between anchoring sites $\mathrm{j}_{\text {wel }}=100 \mathrm{~A} \mathrm{~m}^{-2}$

(B): Radius at detachment versus the half distance between sites relatively to radius at detachment from an isolated site, $r_{s}=150 \mu m, r_{d, i}=1 \mathrm{~mm}$ Figure 12: Acknowledgment figure: The acronym of the project "AMELHYFLAM", the Eiffel tower and ECP for Ecole Centrale Paris "written" with hydrogen bubbles on a vertical $3 \mathrm{~cm}$ diameter copper electrode along a water electrolysis at $\mathrm{j}_{\text {wel }} \sim 100 \mathrm{~A} \mathrm{~m}^{-2}$ 


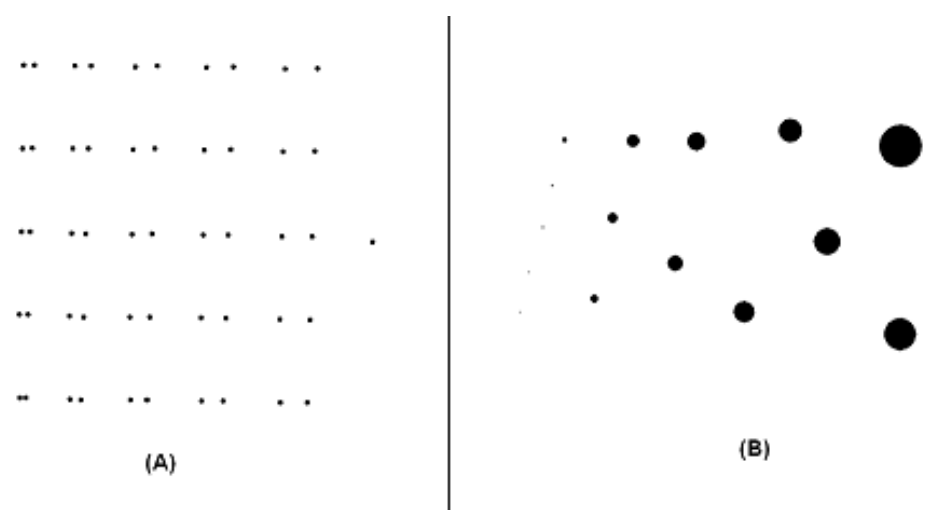

Figure 1: 

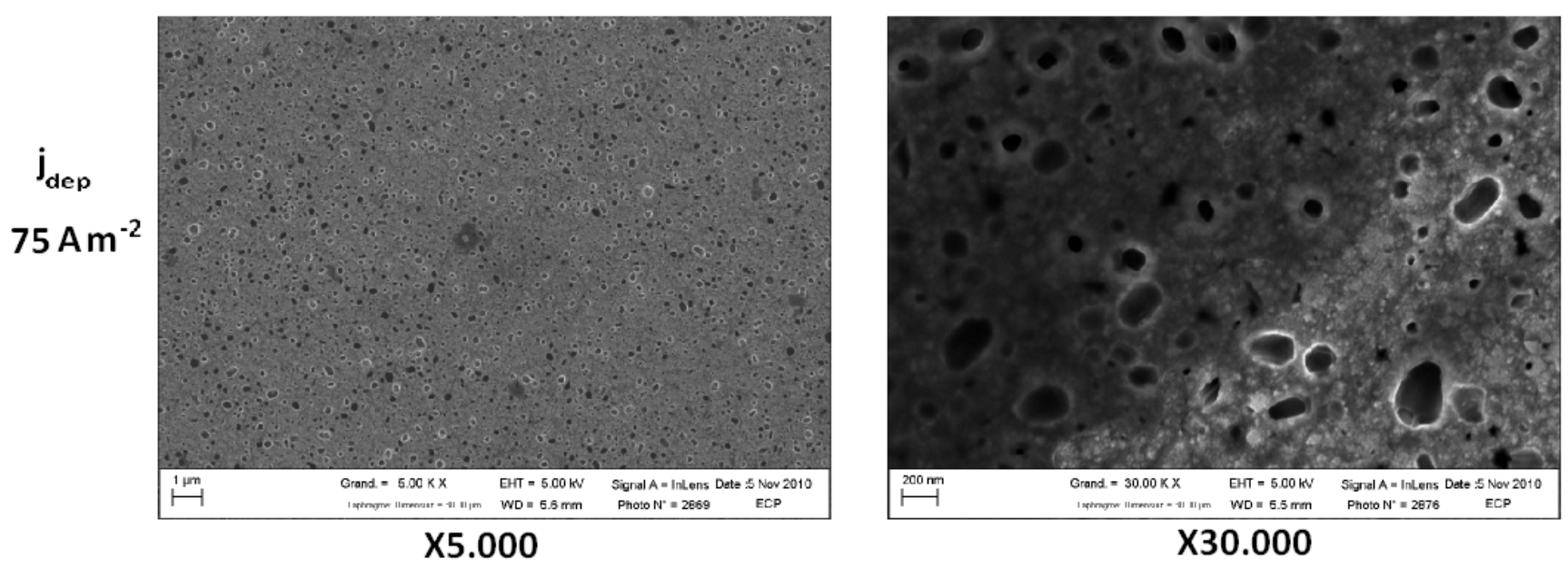

Figure 2: 

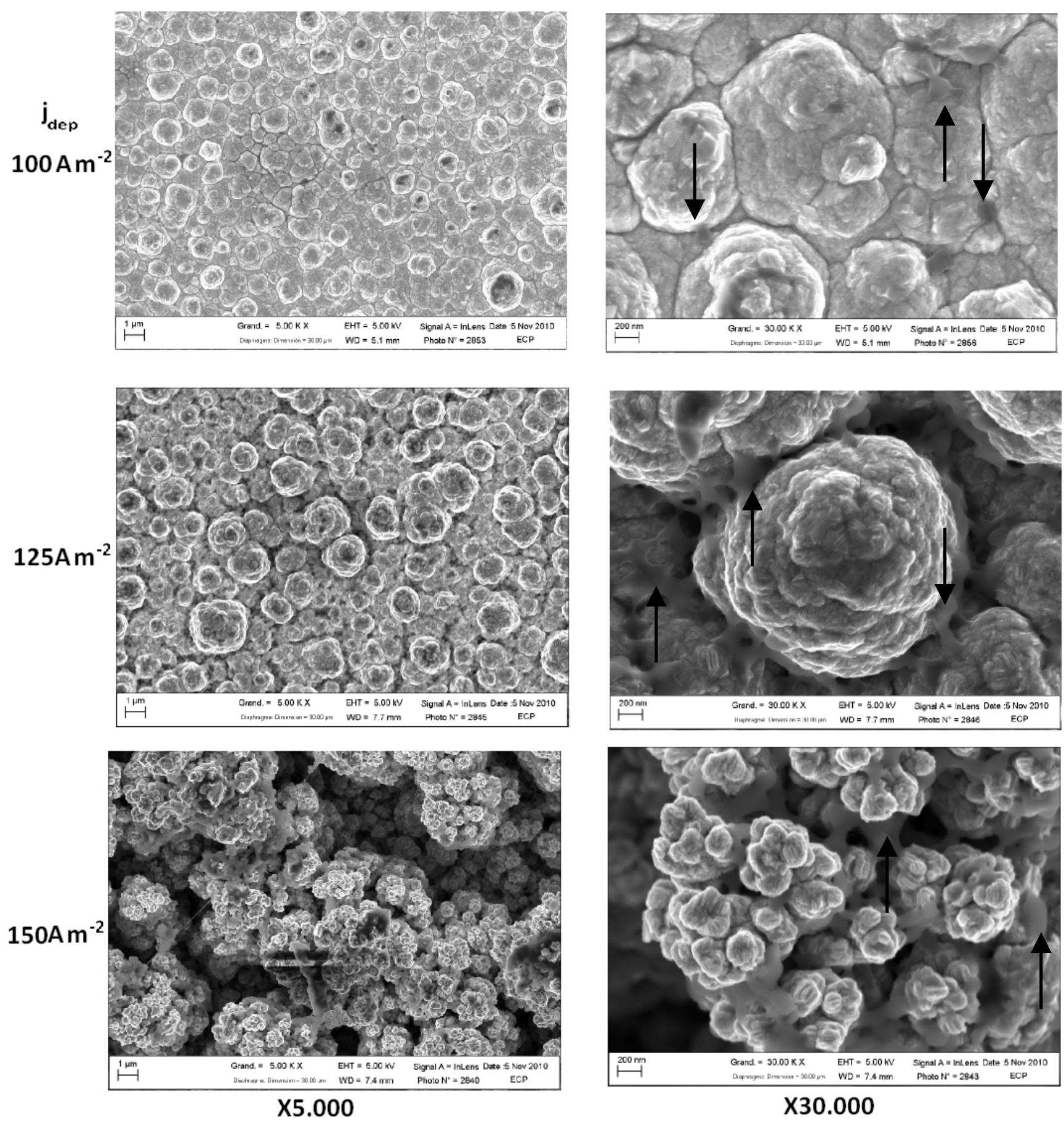

Figure 3: 

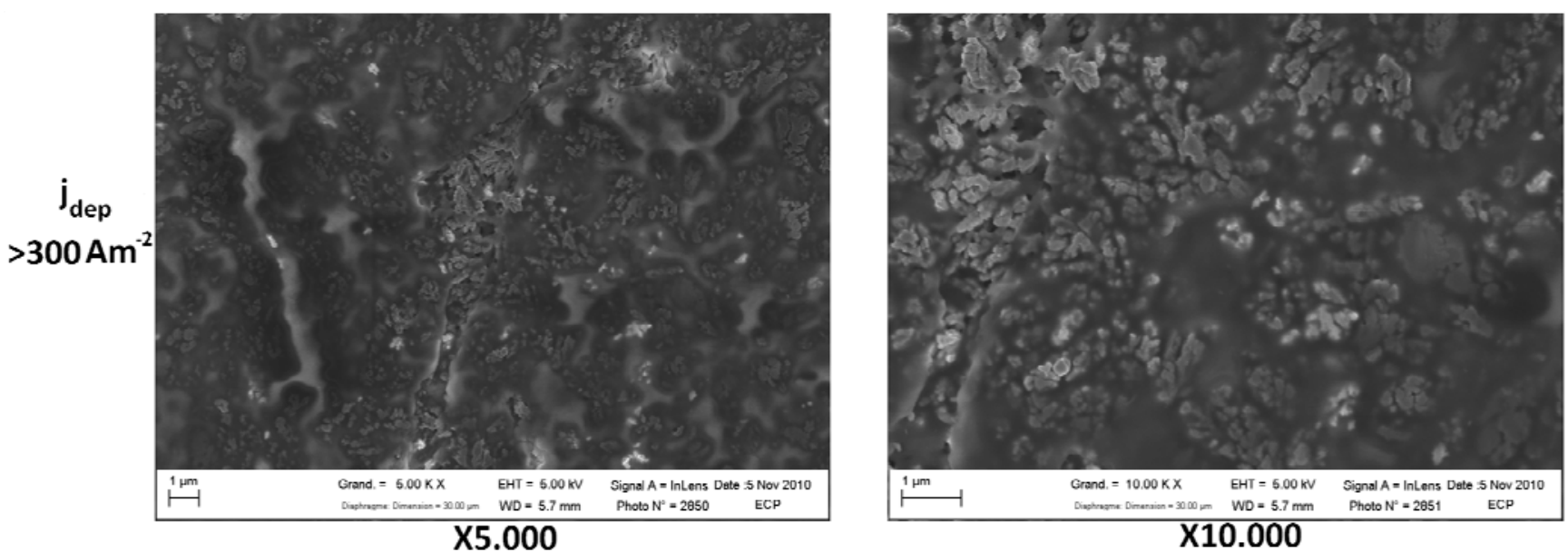

Figure 4: 


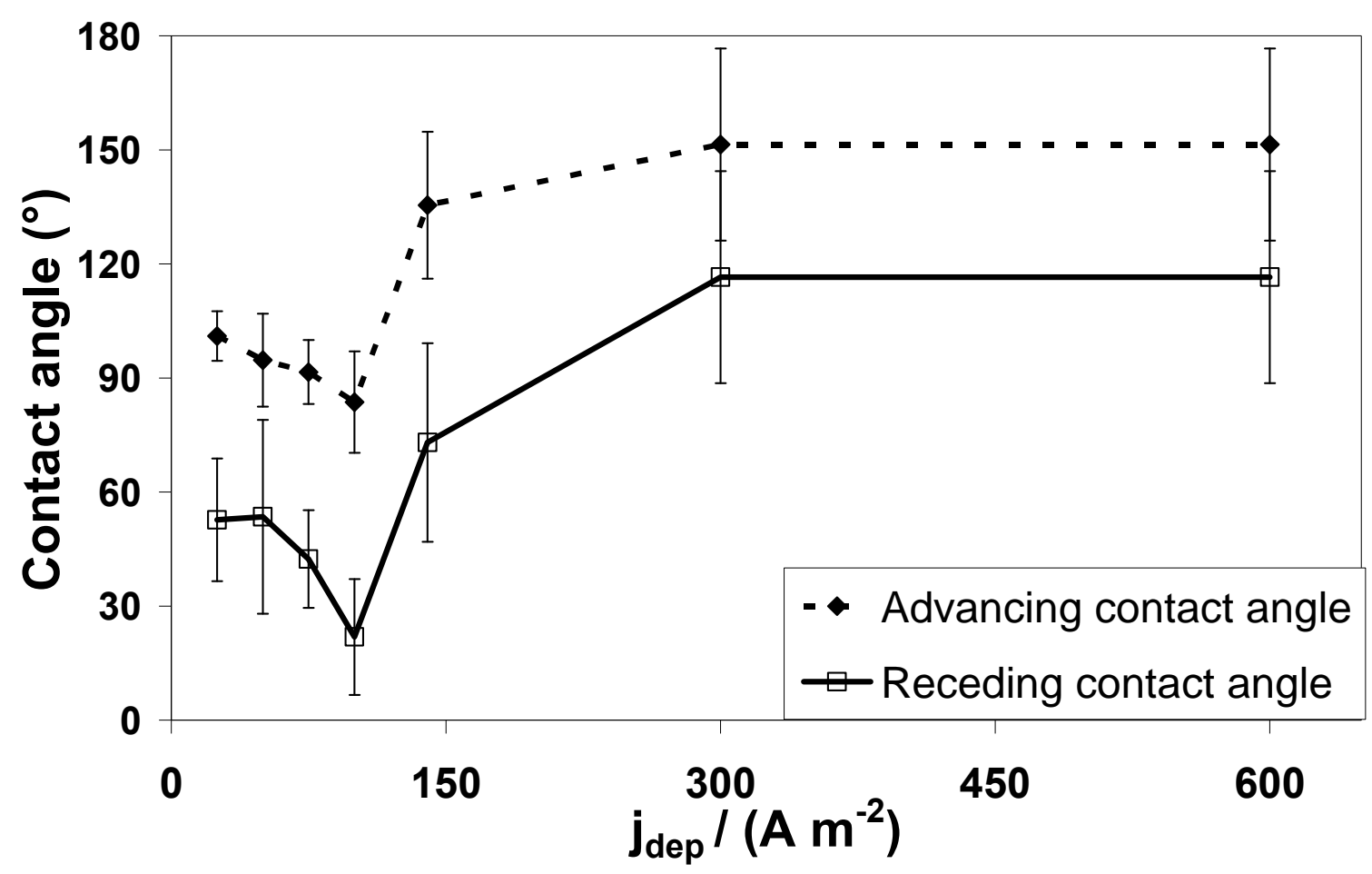

Figure 5: 


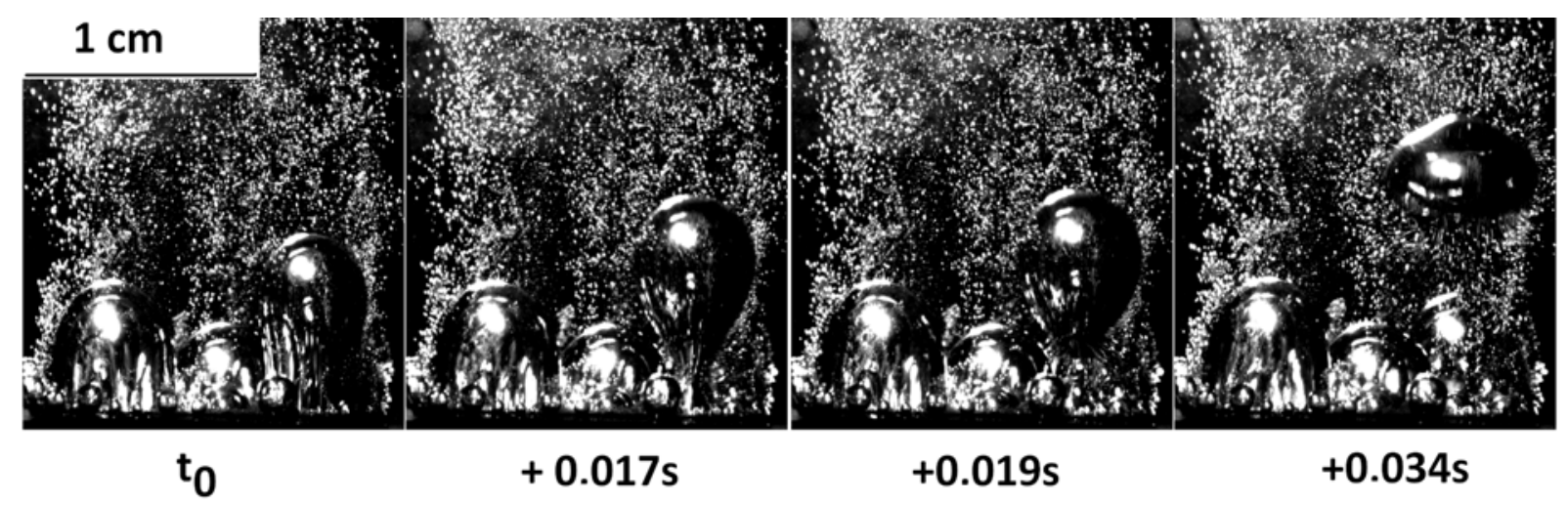

Figure 6: 


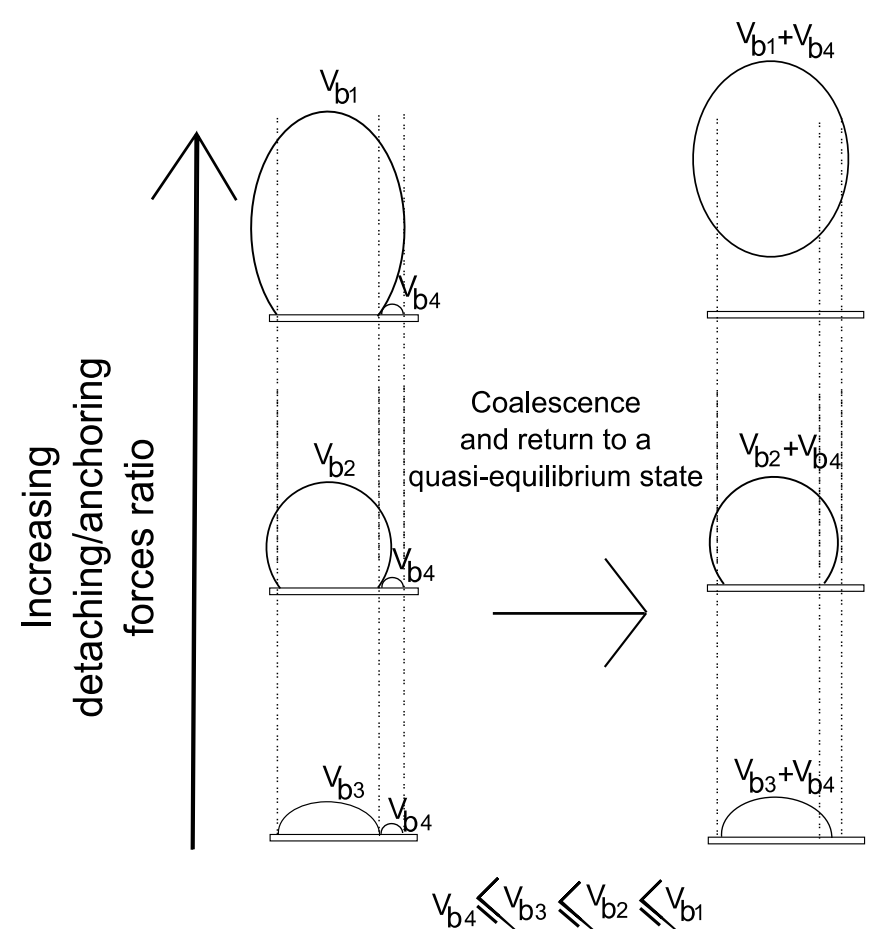

Figure 7: 


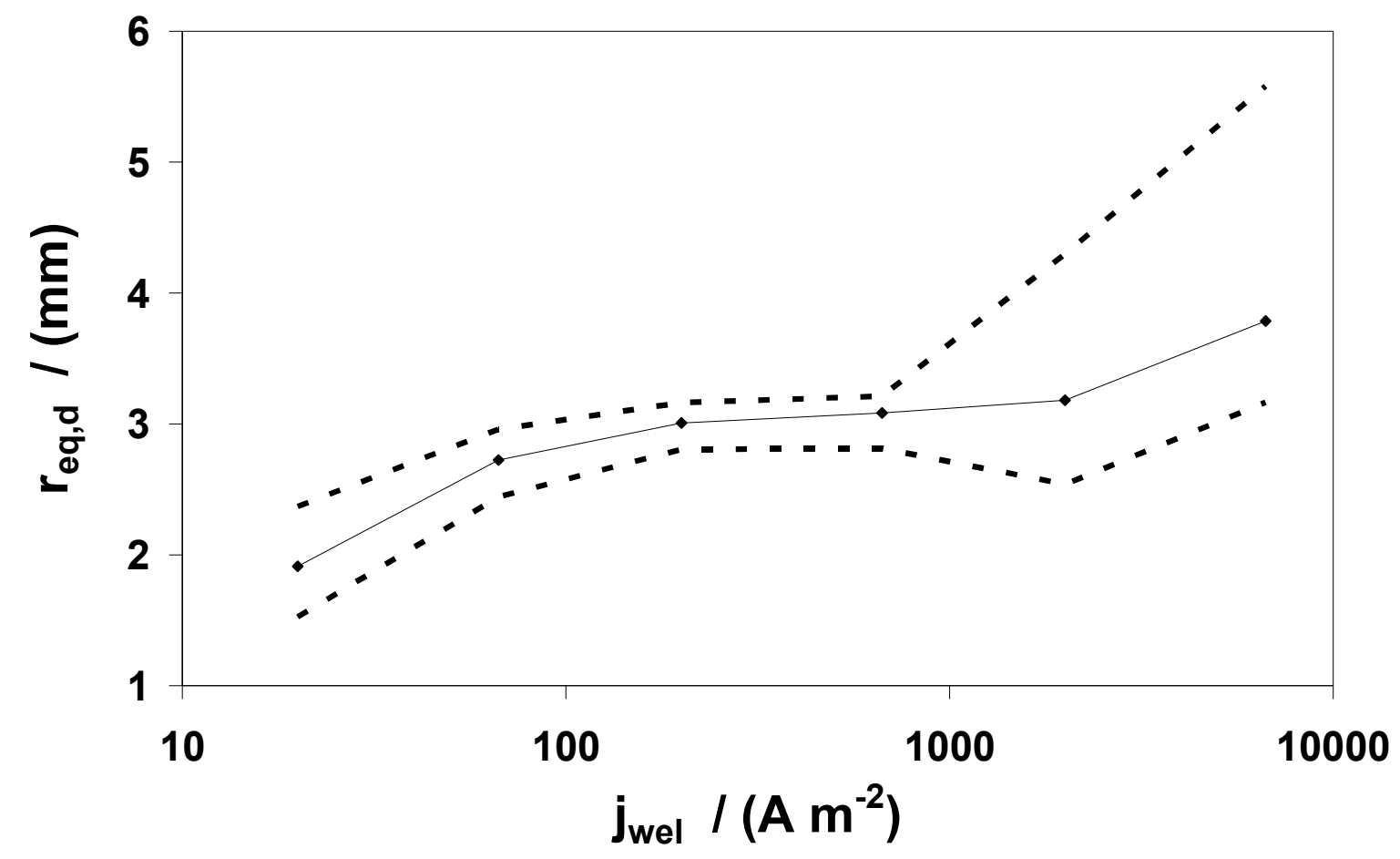

Figure 8: 


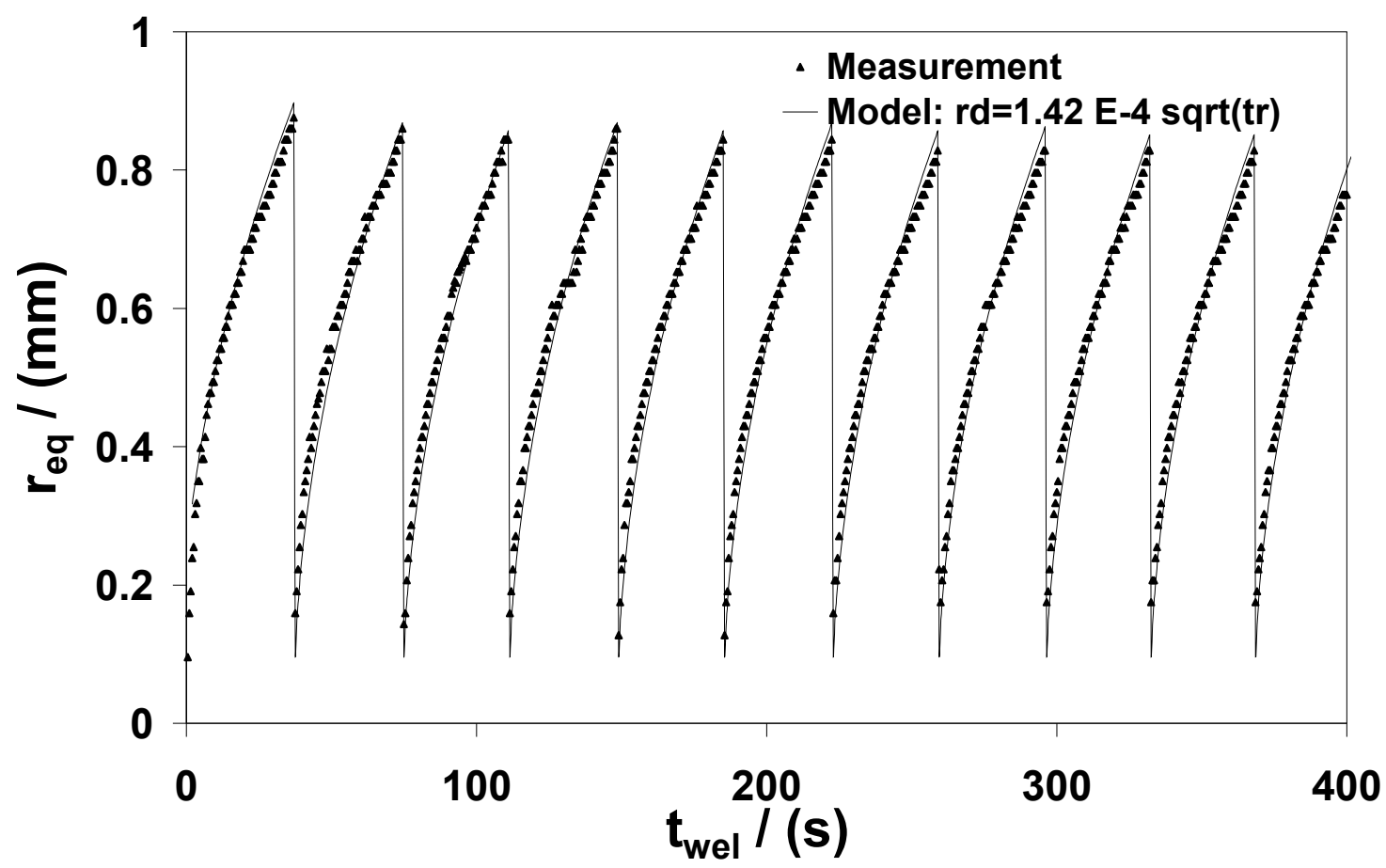

Figure 9: 


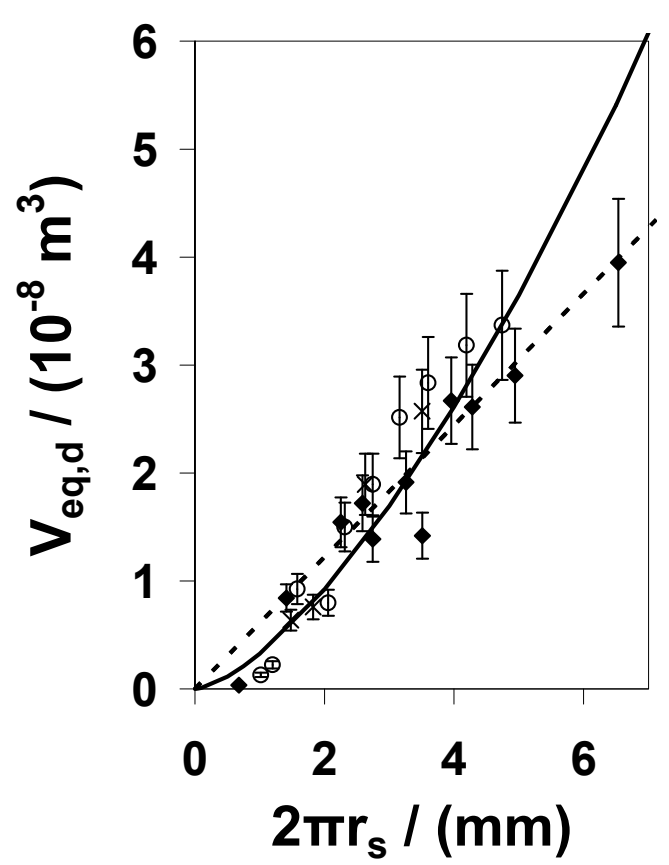

(A)

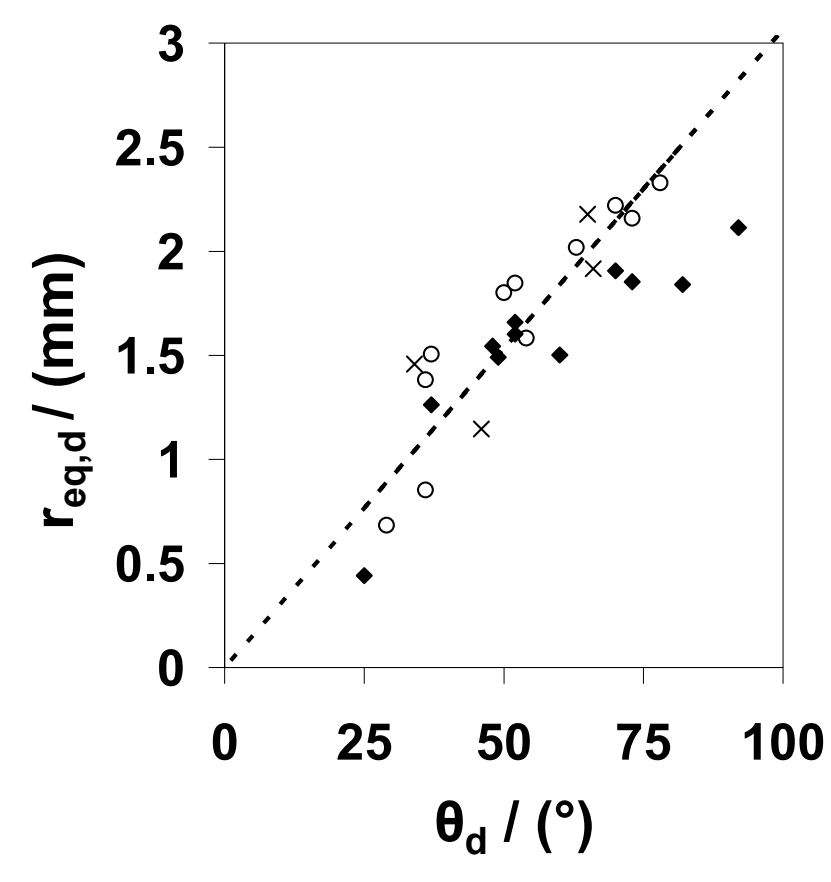

(B)

Figure 10: 


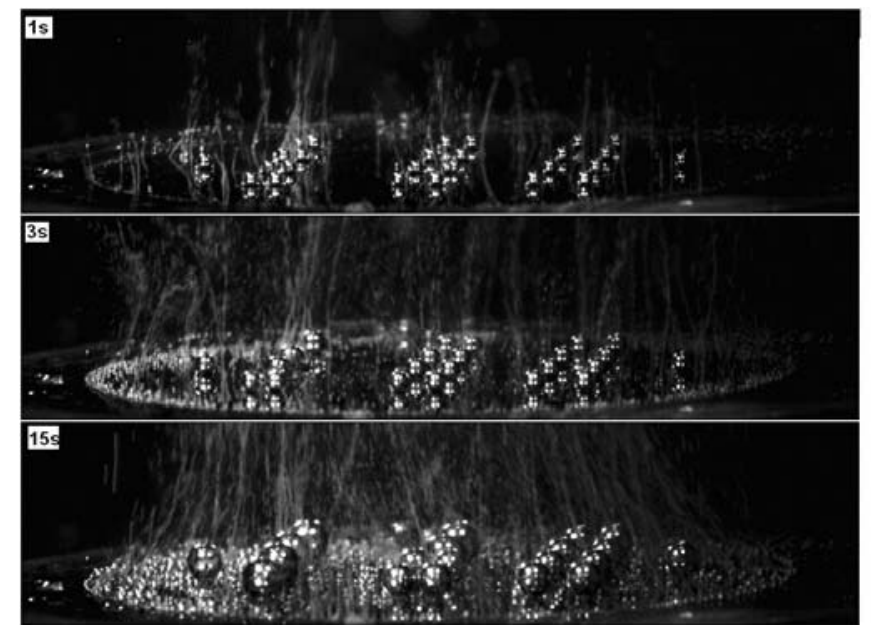

(A)

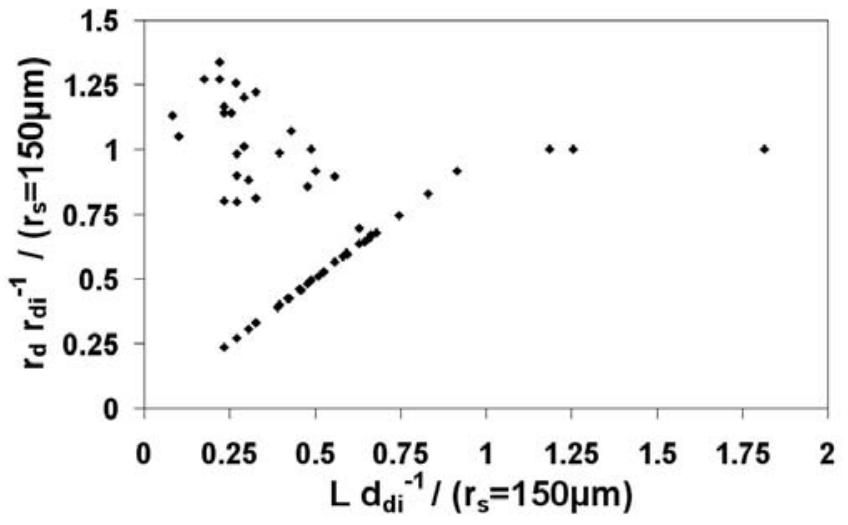

(B)

Figure 11: 


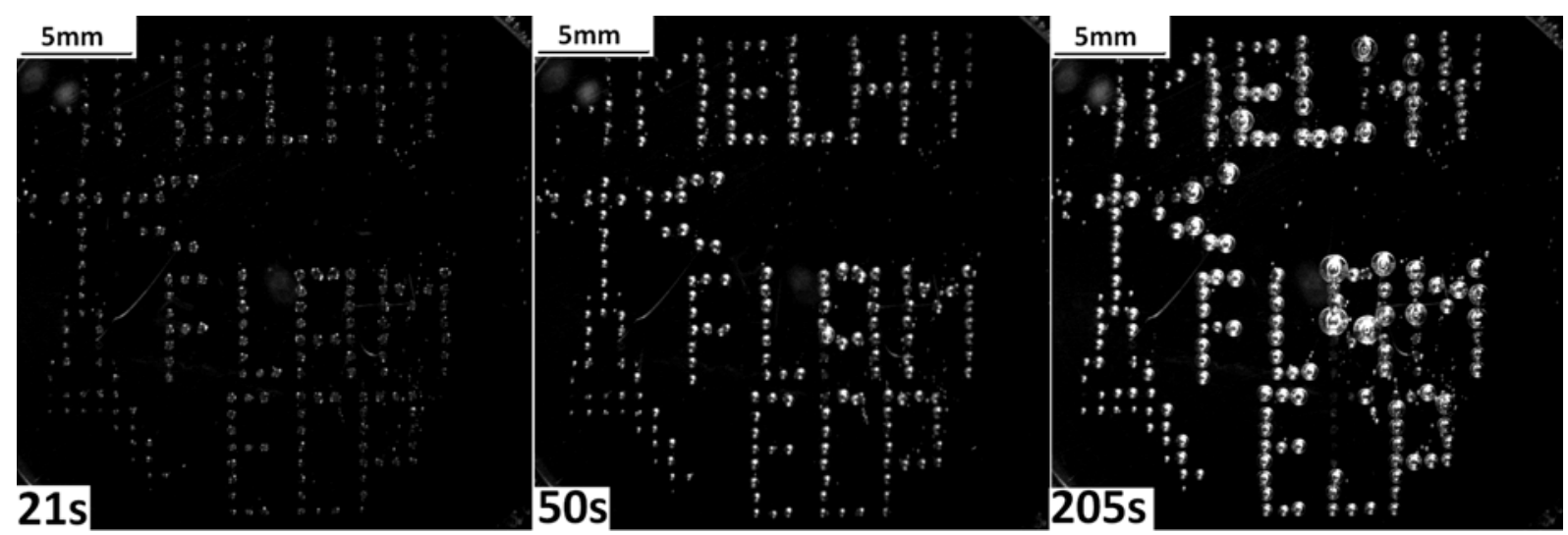

Figure 12: 